(c) <2019>. This manuscript version is made available under the CC-BY-NC-ND 4.0 license http://creativecommons.org/licenses/by-nc-nd/4.0/

The definitive publisher version is available online at https://doi.org/10.1016/j.jclepro.2019.117884 


\title{
Promoting green residential buildings by increasing homebuyers' willingness to pay: Evidence from Sino-Singapore Tianjin Eco-city in China
}

\author{
Yunxia Liu $^{\text {a }}$ Xuan Sun $^{\text {a }}$ Tao Sun $^{\text {a }}$ Xunpeng (Roc) Shi ${ }^{\text {b,c,d,* }}$ Junmin Liu $^{\text {e }}$
}

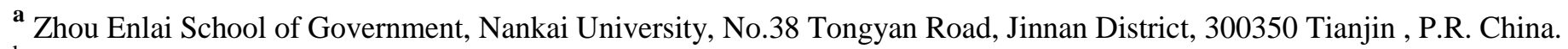

b Australia-China Relations Institute, University of Technology Sydney, Ultimo, NSW 2007, Australia.

${ }^{c}$ Center of Hubei Cooperative Innovation for Emissions Trading System \& School of Low Carbon Economics, Hubei University of Economics, Wuhan, Hubei Province 430205, China

${ }^{\mathrm{d}}$ Energy Studies Institute, National University of Singapore, Singapore 119620, Singapore

${ }^{\mathbf{e}}$ School of Mathematics and Statistics, Xi'an Jiaotong University, No.28, Xianning West Road, Xi'an, Shaanxi, 710049, P.R. China.

*Corresponding author. Xunpeng.shi@gmail.com; xunpeng.shi@uts.edu.au (X. Shi) 


\title{
Promoting green residential buildings by increasing homebuyers' willingness to pay: Evidence from Sino-Singapore Tianjin Eco-city in China
}

\begin{abstract}
Increasing willingness to pay (WTP) is critical to promote green residential buildings (GRBs), but residents' WTP for GRBs has not yet been well studied. To examine residents' WTP for GRBs and its determinants, a survey was conducted of 511 current GRB occupants living in Sino-Singapore Tianjin Eco-city in China, and latent class regression was used to analyze the heterogeneity in their preferences. Four factors of residential satisfaction were identified-operation and maintenance, comfort and health, architectural and construction quality, and accessibility of GRBs - and these determinants of WTP had different effects among different groups of residents. The mean WTP of the majority $(64.5 \%)$ of residents was $374 \mathrm{CNY} / \mathrm{m}^{2}$ (about 54 USD), accounting for only $2.2 \%$ of housing price. Four segments of residents with heterogeneous preferences were identified. The dominant segment (accounting for 64.5\%) was "Indifferent residents with low WTP." The second largest segment (accounting for 18.9\%) was "Critical residents with 1000+ WTP”, followed by the third largest segment (13.3\%) -- "High WTP residents driven by comfort and health", while the smallest segment (3.3\%) was "Operation and maintenance-sensitive residents." The policy implications are that stakeholders should work to enhance the operational performance of GRBs, thereby improving residents' satisfaction and increasing their WTP.
\end{abstract}

Keywords: Green housings; Willingness to pay; Operation and maintenance; Comfort and health; Post occupancy evaluation; Latent class regression 


\section{Introduction}

As a key means of achieving sustainability in relation to the built environment, green residential buildings (GRBs) are becoming increasingly popular in many countries. The promotion of green residential buildings (GRBs) should take a holistic view that includes economic and social sustainability as well as environmental sustainability (Liu et al., 2019a). The initial objective of introducing GRBs was to improve energy efficiency (Song et al., 2018) by saving energy, optimizing the use of resources, and reducing carbon emissions so that GRBs were environmentally friendly (see Fig. 1). Nevertheless, the promotion of GRBs should take into full consideration all of the various stakeholders' trade-offs between economic benefits and costs (Matisoff et al., 2016) as well as various aspects of occupants' social well-being such as comfort (Allen et al., 2015) and health (Zanuzdana et al., 2013), all of which relate to the economic and social sustainability of GRBs (Zuo et al., 2012). Policy-makers in various countries have developed a range of policies aimed at motivating designers, developers, and contractors to embrace GRBs. However, an emphasis on environmental sustainability will not provide sufficient motivation if there is a lack of economic incentive and social acceptance (Liu et al., 2018). Promoting GRBs merely through providing incentives or introducing legislation, regulations and codes, making them mandatory without accompanying economic drivers and social acceptance will not prove sustainable in the long run. Only by addressing residents' well-being (i.e. promoting social sustainability) and delivering the associated benefits can we hope to increase their WTP and thus their demand for GRBs.

Economic, social, and environmental sustainability are interdependent (Ju et al., 2016), and market-oriented mechanisms will help the promotion of GRBs to overcome 
public resistance (Hoffman and Henn, 2008) and lessen the financial burden that governments must incur to stimulate developers to invest in features that provide public goods (i.e. energy savings and environmental protection). Therefore, addressing both economic and social sustainability will help to promote environmental sustainability and increasing willingness to pay is critical to promote green residential buildings (GRBs). By contrast, an approach involving the promotion of environmentally friendly GRBs from the supply side may lead to 1) a mismatch between high design standards and poor operational performance as a result of inadequate management in the operational phase, and 2) an imbalance between supply and demand as a result of potential occupants' lack of positive residential experiences (Liu et al., 2019b).

\section{Insert Fig. 1 here}

This study is related to two strands of literature. One is the measurement of residential satisfaction, while the other is the measurement of WTP and the identification of its driving factors. Residents' WTP affects the price premium that can be charged, and hence the economic sustainability of GRBs. While residential satisfaction is an important indictor used to measure the improved residents' well-being that is supposed to be provided by GRBs, it is also a measure of social sustainability. In this study, we investigate whether residents' satisfaction can predict their WTP, that is, whether social sustainability can promote economic sustainability. Investigating residents' WTP is of great importance because it indicates the price premium that consumers are prepared to pay for GRBs compared with traditional buildings, and thus affects the price of GRBs. If residents' WTP for GRBs is lower than the additional cost of producing GRBs, developers have no motivation to develop green housing (Deng and $\mathrm{Wu}, 2014)$. Under this circumstance, governments will need to provide subsidies to 
GRB developers if they wish to promote production of GRBs. Therefore, residents' WTP is critical information for a government trying to determine the amount of incentives that they must provide for GRB development.

In this study, we focus on the WTP of current occupants of GRBs, rather than that of prospective buyers, and we also focus on the influence of residential satisfaction, rather than that of psychological or sociodemographic factors for two reasons. First, data are more objective and rational in relation to our chosen areas of focus. GRBs are durable, multifunctional goods, and residents' WTP relies more on their living experiences than on any psychological or sociodemographic factors. Only if people live in a GRB for a period of time can they obtain a sense of the building's usefulness and value, and thus form a rational sense of their WTP. GRBs are also post-experience goods. Prospective consumers, who have no experience living in GRBs, are unable to perceive the merits of GRBs compared with traditional buildings, and thus their WTP provides little information. Second, our findings are more enlightened because current residents' WTP is influenced by their living experience and subsequent evaluation. Experience-based feedback can help policy-makers to identify problems in the operational phrase (i.e. barriers limiting residents' WTP) and improve the operational performance of GRBs, which can enable them to develop appropriate strategies to attract various groups of prospective residents and increase their WTP.

This study addresses the following research questions:

1) What is the current occupants' WTP a price premium for GRBs? How does it vary among different groups of occupants?

2) What is the internal structure of occupants' residential experiences in various 
aspects? Does residential satisfaction affect WTP?

This study contributes to the literature as follows. First, we provide empirical evidence through post-occupancy evaluation (POE) of GRBs, in particular from the occupants' perspective in the case of mainland China. To the best of our knowledge, no previous POE studies have covered so many GRBs in mainland China. Second, we examine heterogeneity in relation to residents' preferences regarding WTP and its determinants, which has not previously been well studied. Residents' WTP a price premium for GRBs will provide a reference point for developers' cost-benefit analyses, and hence their production behavior, as well as for government incentive schemes.

The rest of the paper is organized as follows. Section 2 presents a literature review, Section 3 outlines the methodology, including data collection and analytic tools, Section 4 presents the survey results, and Section 5 discusses the results and implications. Section 6 presents conclusions and the future outlook.

\section{Literature review}

\subsection{Measuring residential satisfaction}

Residential satisfaction is a key indicator of the operational performance of GRBs. Previous studies have analyzed occupants' residential satisfaction from different perspectives. The first group of studies focused on the comfort and health of residents' indoor or outdoor environment, including indoor air temperature and quality, acoustics, and lighting in UK eco houses (Zeng et al., 2018), indoor environment quality (IEQ) in Leadership in Energy and Environmental Design (LEED) system-certified buildings in the US (Altomonte and Schiavon, 2013), and soundproofing, natural lighting, thermal comfort, and indoor air quality to analyze 
occupants' satisfaction with the IEQ of certified green office buildings in Taiwan (Liang et al., 2014). The second group of studies investigated the operation and maintenance of GRBs, including cleaning (Huang et al., 2015) and maintenance and repairs (Lai, 2011). The third group of studies investigated architectural design aspects (Bonaiuto et al., 2015), while the fourth group of studies focused on the availability and accessibility of public and commercial resources, including transport (Li, D. et al., 2014), commercial facilities (Huang et al., 2015), and public facilities (Zhan et al., 2018).

However, most of the empirical evidence in these studies was from buildings certified by LEED, the Building Research Establishment Environmental Assessment Method (BREEM), or other rating systems. Most of these emphasize environmental factors rather than social factors (Baird et al., 2012), and social sustainability and economic sustainability are seldom discussed (Zhang, 2015). Furthermore, most of the evidence was obtained from office buildings rather than residential buildings. Evidence from mainland China focusing on China's Green Building Label (GBL) projects is emerging, but remains inadequate in terms of both quantity and building type.

\subsection{Drivers of residents' WTP}

Several researchers have examined the drivers of WTP among conventional building residents. A study based on China's five first-tier cities showed that the drivers of residents' WTP varied for different groups of residents. Some invested in GRBs for their potential appreciation in value, while others purchased GRBs in search of a more comfortable living environment ( $\mathrm{Li}$ et al., 2018). Another study based on Nanjing in China showed that socioeconomic status was the main driver of residents' WTP, noting that wealthier people are prepared to pay a premium for the more 
comfortable living conditions provided by GRBs, and thus the healthier environment was a selling point for all residents (Hu et al., 2014).

Few studies have quantified residents' WTP and identified its influencing factors. A study in Sweden revealed the perceived importance of energy and environmental factors as determinants of stated WTP, and found that purchasers were prepared to pay a 5\% premium for low-energy buildings (Zalejska-Jonsson, 2014). A nationwide online survey in Israel found that expected maintenance savings was a driver of WTP, and identified an acceptable green building premium of 7\%-10\% (Portnov et al., 2018)

WTP studies comparing GRB residents and conventional building residents have also been conducted. In Hong Kong, both groups were reported to have strong preferences and were willing to pay more for various improvements in environmental performance in GRB developments (Chau et al., 2010). The study from Sweden showed that green residents are generally more willing to pay extra for GRBs (Zalejska-Jonsson, 2014). The findings of the study from Sweden were echoed by those of a study based in Beijing, which found that once information was provided to non-green residents, their WTP increased and the difference between their WTP and that of green residents narrowed (Zhang et al., 2016).

Studies have often found that residents' private benefits are the main drivers of their WTP. For example, a study in Hong Kong found that residents' WTP was mainly motivated by economic reasons, rather than moral or altruistic reasons. Green housing attributes that reduced residents' utility bills led to greater WTP (Yau, 2012). In Israel, it was reported that each percentage point of expected maintenance savings increased WTP by $0.3 \%$ of the price of the house (Portnov et al., 2018). 
In general, previous studies have presented preliminary findings regarding the drivers of WTP. However, the study samples have mainly included prospective GRB buyers rather than current residents, and thus the findings may be biased, and the implications uncertain. Moreover, the object they investigated was the extent of willingness to buy, that is, the intention to buy, rather than the WTP a price premium. Therefore, further insight into the extent of current residents' WTP is required.

\section{Methodology}

\subsection{Data collection and cleaning}

Data were collected using a questionnaire with three parts. Part 1 investigated occupants' satisfaction with various indicators that were selected based on the literature review. A five-point Likert scale was used to quantify the occupants' level of satisfaction $(1=$ very dissatisfied, $2=$ dissatisfied, $3=$ neutral, $4=$ satisfied, $5=$ very satisfied). Part 2 asked residents to nominate their WTP, that is, the additional amount they would be prepared to pay $\left(\mathrm{CNY} / \mathrm{m}^{2}\right)$ for a GRB compared with a traditional building. Part 3 collected information on the residents' sociodemographic backgrounds.

Sino-Singapore Tianjin Eco-city (hereafter referred to as Eco-city) in China was selected as the sample site. Eco-city is an international cooperative project between China and Singapore that celebrated its 10 -year anniversary in 2018, coinciding with the 10-year anniversary of the commencement of China's green building projects. All of the buildings in Eco-city, both residential and non-residential, must meet green building standards and be certified with GBLs. 
With the help of the local government and the Green Building Research Institute in Eco-city, an online survey was conducted among adult residents in Eco-city from July to November 2017. Convenience sampling was used, and trained investigators gained access to Eco-city's internal social media platforms. Residents using these platforms were informed about the objectives and background of the survey, and were offered a reward for completion of the survey. Of the 1,656 residents who opened the questionnaire, 630 residents finished and submitted their questionnaires, with a response rate of $38 \%$. After the data clean progress, 511 valid questionnaires left for follow-up analysis, accounting for $81.1 \%$ of collected questionnaires.

Among the 511 respondents, male and female residents account for $45.4 \%$ and $54.6 \%$ respectively (Table 1). Residents age in 31-40 accounted for about a half (54.4\%), followed by those in their 19-30 years old (33.5\%). $44.2 \%$ of them have a monthly income of 5,001-10,000 yuan, followed by those with a monthly income less than 5000 yuan (36\%). Most of them (61.8\%) live there for 1 or 2 years and $87.5 \%$ of respondents are owners rather than tenants.

\section{Insert Table 1 Here}

There are $30.9 \%$ of investigated residents live in the $10^{\text {th }}$ or above floor, followed by those live in the $4^{\text {th }}-6^{\text {th }}$ floor $(29.9 \%) .37 .6 \%$ of respondents' apartments have 2 bedrooms and 1 living room, followed by those live in an apartment with more than 3 bedrooms and 2 living rooms $(25.0 \%)$. The 511 respondents come from 26 residential estates in Eco-city (Table 2). All of them adopt central heating provided by municipality in winter, the heating fee is $25 \mathrm{CNY} / \mathrm{m}^{2}$. The cooling in summer rely on households' own air conditioners. Majority of them are multi-level high-rise buildings. Plot ratios for most of these estates range 1.0-2.0. The ratio of green space range from 
$25 \%$ to $50 \%$, but for most of the residential estates, the ratio is about $40 \%$. The building maintenance and service are operated by property management companies. Owners pay management fees bases on areas of their apartments.

\section{Insert Table 2 Here}

\subsection{Latent class regression}

Latent class regression, which is a popular tool for analyzing preference heterogeneity, was used. In latent class analysis, we assume that there is a latent, or unobservable, categorical variable $\mathrm{X}$, which has $\mathrm{k}$ different categories, that is, latent classes (Vermunt and Magidson, 2005). Samples within each latent class are similar in some ways, while cases in different latent classes are heterogeneous in some ways (Vermunt and Magidson, 2002). Thus, latent class analysis differs from factor analysis and structural equation modelling, both of which require the latent class to be continuous (Vermunt and Magidson, 2005).

Latent class regression differs from traditional regression in that the coefficients differ for various classes. An important assumption in relation to latent class regression is that samples are heterogeneous. Different groups of people are affected by different determinants, and thus we cannot identify people's preferences and their determinants by calculating a set of corresponding coefficients for the proposed determinants. Instead, we may arrive at different sets of coefficients for the given determinants, which means that the coefficients of the given determinants vary among different classes of people. For example, in the present study, the WTP of one class of residents may be highly influenced by comfort and health but not sensitive to accessibility, while the WTP of another class of residents might be mainly influenced by accessibility but insensitive to comfort and health. 


\section{Results}

\subsection{Level and dimension of residential satisfaction}

\subsubsection{Level of residential satisfaction}

Residents' residential satisfaction scores were regrouped to obtain an overview of their attitudes toward different indicators. Scores of 1 or 2 were grouped to represent a negative attitude, while scores of 4 or 5 were grouped to represent a positive attitude. The distribution of the residents' evaluations of their residential experiences is shown in Fig. 2. In general, GRBs provided a more comfortable and healthy living environment based on the relevant indicators. Outdoor air movement satisfied $71.23 \%$ of residents, followed by thermal comfort in winter (67.32\%), indoor daylight $(65.17 \%)$, and indoor ventilation $(64.58 \%)$. By contrast, their performance in terms of operation and maintenance, and architectural and construction quality were relatively poor. The services provided by property management companies and soundproofing were deemed unsatisfactory by $42.07 \%$ of residents, while $35.23 \%$ were dissatisfied with the maintenance of facilities and $33.86 \%$ were dissatisfied with the construction quality. It should be noted that $97.46 \%$ of residents reported a neutral attitude toward publicity regarding energy-saving behaviors. This indicator was deleted in the following analysis because limited information was provided.

\section{Insert Fig. 2 here}

The overall performance of each indicator was represented by the mean of the respondents' scores. Occupants' residential satisfaction in terms of the various indicators is shown in Fig. 3. The mean scores ranged from 2.73-4.00, indicating that residents had a positive attitude in relation to most of the indicators, with the exception of construction quality and soundproofing. Outdoor air movement attracted 
the highest score, followed by thermal comfort in winter.

\section{Insert Fig. 3 here}

\subsubsection{Dimension of residential satisfaction}

In the present study, more than 20 indicators were used to measure residents' satisfaction. However, these indicators were unable to be used directly, as 22 independent variables may be collinear thus data reduction was needed. Principle component analysis was used to explore the underlying dimensions of occupants' residential satisfaction. The values from the Kaiser-Meyer-Olkin test of sampling adequacy (0.93) and Bartlett's test of sphericity (0.00) indicated that the data dimension was necessary and useful. Varimax rotation, an orthogonal rotation method, was used for analysis. The results are shown in Table 3. Four extracted components explained $60.5 \%$ of the total variance.

\section{Insert Table 3 here}

There were seven indicators included in component 1, namely, property management services, facility maintenance, cleanliness of residential estates, greening of residential estates, energy saving in public areas (e.g. corridors and staircases), traffic layout and management within residential estates, and drainage of residential estates. These indicators were more related to the operation and maintenance of GRBs, hence we labeled component 1 the "Operation and maintenance dimension," which explained $39.6 \%$ of the total variance.

Component 2 included six indicators with high loadings, namely, indoor lighting, ventilation, air quality, thermal comfort in winter, thermal comfort in summer, and outdoor air movement. These factors influenced occupants' comfort and health, hence 
component 2 was labeled the "Comfort and health dimension," which accounted for $10.5 \%$ of the total variance. Component 3 also included six indicators with high loadings, namely, soundproofing, construction quality, thermal insulation, airtightness of windows, quality of power supply facilities, and outdoor noise. Compared with the indicators in component 1 , these indicators were more dependent on professional and technical expertise in the planning, design, and construction phases. Therefore, we labeled component 3 the "Architectural and construction quality dimension," which accounted for $5.8 \%$ of the total variance. Accessibility to public transportation and availability of shopping, catering, and leisure facilities were included in component 4, which was labeled the "Accessibility dimension" and explained $4.6 \%$ of the total variance. The various dimensions of residential satisfaction are shown in Fig. 4. The scores in relation to each of the four principal components were calculated for each resident.

\section{Insert Fig. 4 here}

\subsection{Heterogeneity of residents' WTP}

The WTP of $23.7 \%$ of the residents ranged from 1000 to $2000 \mathrm{CNY} / \mathrm{m}^{2}$, while that of nearly $20 \%$ of residents was less than $10 \mathrm{CNY} / \mathrm{m}^{2}$, that of $15.1 \%$ of residents ranged from 100 to $500 \mathrm{CNY} / \mathrm{m}^{2}$, and that of $15.0 \%$ of residents' WTP are greater than or equal to 500 but less than $1000 \mathrm{CNY} / \mathrm{m}^{2}$ (Table 4). The mode was 1000 $\mathrm{CNY} / \mathrm{m}^{2}$, with a frequency of 112 , accounting for $21.9 \%$ of the overall sample, followed by $1 \mathrm{CNY} / \mathrm{m}^{2}$ and $500 \mathrm{CNY} / \mathrm{m}^{2}$, which accounted for $15.7 \%$ and $14.1 \%$, respectively, of the overall sample.

\section{Insert Table 4 here}




\subsubsection{Deciding on the optimal number of classes}

The first step was to choose the optimal number of classes. This is important because too few classes may result in a loss of information that is needed to explain variances among different classes, while too many classes may prove technically unstable and make little sense empirically. The optimal number of classes was determined based on several model-fit indicators.

The Akaike information criterion (AIC) and Bayesian information criterion (BIC) are important criteria used to determine the optimal number of clusters. The AIC is an estimator of the relative quality of statistical models in relation to given data, and provides an effective means of model selection:

$$
\mathrm{AIC}=-2 \ln \mathrm{L}+2 \mathrm{k}
$$

Where $\mathrm{L}$ denotes logarithmic likelihood value and $\mathrm{k}$ denotes the number of parameters.

The BIC is another criterion used for model selection. Generally, the model with the lowest BIC and the minimum number of classes is preferred. The BIC is based on the likelihood function and is closely related to the AIC:

$$
\mathrm{BIC}=-2 \ln \mathrm{L}+\mathrm{k} * \ln (\mathrm{n})
$$

Where $\mathrm{L}$ denotes the likelihood, $\mathrm{n}$ is the number of observations, and $\mathrm{k}$ is the number of parameters. In general, the smaller the values of the BIC and the AIC, the better. However, there is no clear-cut criteria. When deciding on the optimal number of classes, all model-fit indicators should be assessed holistically, 
especially in relation to the plausibility, parsimony, and explanatory power of the models.

We estimated eight types of models ranging from a 1-class model to an 8-class model. The estimation results are shown in Table 5. The minimum BIC value occurred in relation to the 3-class model, indicating that this was the optimal model. However, it explained only $81 \%$ of the variance. Given that the minimum positive AIC value occurred in relation to the 4-class model, and the explanatory power increased to $85 \%$, we chose the 4-class model for further analysis.

\section{Insert Table 5 here}

\subsubsection{Profile and preference heterogeneity among different classes}

There were four different classes of residents identified in the latent class regression model (see Table 6). The results showed that the mean WTP of the Class 1, Class 2, Class 3, and Class 4 residents was 374, 1284, 12,575, and $2566 \mathrm{CNY} / \mathrm{m}^{2}$, respectively. Given that the average house price in Eco-city was about $17,000 \mathrm{CNY} / \mathrm{m}^{2}$ in 2017 , the WTP as a percentage of the house price was $2.2 \%, 7.6 \%, 74.0 \%$, and $15.1 \%$ for Class 1 , Class 2, Class 3, and Class 4, respectively.

Coefficients $(\beta)$ for predictors were estimated for each class. The Wald test showed that all four components played a significant role in explaining the WTP $(\mathrm{p}=0.1)$. However, their influence varied in relation to different classes of residents $(\mathrm{p}=0.1)$. Class 1 and Class 3 residents' WTP a price premium for GRBs was mainly driven by comfort and health. Regarding the covariates, duration of residence played a similar role, in that Class 1 and Class 3 residents were more likely to have lived in a GRB for less than two years. However, comfort and health played a far greater role in 
the WTP of Class 3 residents $(\beta=0.21)$ than in that of Class 1 residents $(\beta=0.02)$. In addition, the two classes differed with respect to age. Class 3 residents tended to be either 18-30 years old or more than 40 years old.

\section{Insert Table 6 here}

Class 1 residents' mean WTP was $374 \mathrm{CNY} / \mathrm{m}^{2}$, the lowest of the four classes, and they were indifferent toward all four factors (with the exception of a slight interest in comfort and health). Therefore, we labeled them "Indifferent residents with low WTP." Class 1 residents accounted for $64.5 \%$ of the overall sample. By contrast, Class 3 residents' mean WTP was $12,575 / \mathrm{m}^{2}$, the highest among the classes by far, and the only class to exceed $10,000 \mathrm{CNY} / \mathrm{m}^{2}$. Hence, we labeled them "High WTP residents driven by comfort and health of green housing." Class 3 residents accounted for $13.3 \%$ of respondents.

Class 2 residents were positively influenced by comfort and health, and architectural and construction quality, but negatively influenced by accessibility. They tended to be wealthier, and their monthly income was likely to be more than 10,000 CNY. Their mean WTP was $1284 \mathrm{CNY} / \mathrm{m}^{2}$. Hence, we labeled them "Critical residents with $1000+$ WTP.” Class 2 residents accounted for $18.9 \%$ of the overall sample.

Class 4 residents attached great importance to operation and maintenance, and were prepared to sacrifice comfort and health, and accessibility to GRBs for greener, cleaner, better management of their living environment. Their mean WTP was 2566 $\mathrm{CNY} / \mathrm{m}^{2}$. Thus, we labeled them "Operation and maintenance-oriented residents with 2000+ WTP." Class 4 residents accounted for only 3.3\% of the overall sample. 
The profiles of the residents in the four classes are summarized in Table 7. In Class $1,60 \%$ of residents were female, $51.4 \%$ were in their thirties, only $9.6 \%$ of them had a monthly income of more than 10,000 CNY, and $67.3 \%$ of them had arrived within the previous two years. In contrast, 58\% of residents in Class 3 were male. In Class 2, 62\% of residents were male and $65.2 \%$ were aged between 30 and 40. In Class 4, 98.2\% of residents were female, $95.5 \%$ were aged between 31 and 40, and $65.2 \%$ had been in residence for 3-4 years.

\section{Insert Table 7 here}

In summary, the dominant class (accounting for $64.5 \%$ of the overall sample) was labeled "Indifferent residents with low WTP" because their mean WTP was only $374 \mathrm{CNY} / \mathrm{m}^{2}$ (about $54 \mathrm{US}$ dollars). In this class, $60 \%$ of residents were female and $67 \%$ had been in residence for up to two years at the time of the survey in 2017 . The second largest segment (accounting for $18.9 \%$ of the overall sample) was labeled "Critical residents with 1000+ WTP" because residents in this segment were sensitive to several factors (i.e. architectural and construction quality, comfort and health, and accessibility) and their mean WTP was $1284 \mathrm{CNY} / \mathrm{m}^{2}$ (about 187 US dollars). Approximately $50 \%$ of residents in this segment had a monthly income of 5000-10,000 CNY. The third largest segment (accounting for $13.3 \%$ of the overall sample) was labeled "High WTP residents driven by comfort and health" because their mean WTP was $12,575 \mathrm{CNY} / \mathrm{m}^{2}$ (about $1828 \mathrm{USD}$ ). Residents aged 50 or more were more likely to be included in this segment. The smallest segment (accounting for just $3.3 \%$ of the overall sample) was labeled "Operation and maintenance-sensitive residents." Their mean WTP was $2566 \mathrm{CNY} / \mathrm{m}^{2}$ (about $373 \mathrm{USD}$ ). Residents in this segment were dominated by females and those who had been in residence for 3-4 
years. A summary of the four different segments of residents in terms of drivers and levels of WTP is shown in Fig. 5.

\section{Insert Fig. 5 here}

\subsection{Determinants of residents' WTP}

The results show that comfort and health is a common determinant of WTP for all four types of residents. This echoes the findings of previous studies focused on mainland China (Hu et al., 2014; Li et al., 2018) and Hong Kong (Chau et al., 2010), which also found that the healthier environment provided by GRBs was a selling point for residents. Combined with residential satisfaction indicators, sociodemographic features help to explain residents' WTP, but they play different roles for different groups of residents. It should be noted that a single sociodemographic factor is unable to predict WTP. Taking age as an example, residents in their thirties may be classified as either "Critical residents with $1000+$ WTP” or "Operation and maintenance-oriented residents with 2000+ WTP." Further, females showed different levels of WTP, and appeared in all four groups. This result differed from that of a previous study ( $\mathrm{Li}$ et al., 2018), which found that female residents showed a higher WTP.

The performance of GRBs in terms of energy efficiency did not have a significant influence on residents' WTP. The majority (98\%) of residents' were indifferent to publicity and information campaigns on energy-saving behaviors, and even in relation to the indicator "energy saving in public areas," $49.7 \%$ expressed neither dissatisfaction nor satisfaction. The reason for residents' low level of interest in energy saving in relation to the entire residential estate may be that it provides no direct benefit to them. Similar to carbon emissions reduction and resource-optimizing 
features, the benefits of energy saving through building operation and maintenance are public benefits rather than private residents' benefits. Public benefits are more related to GRBs' contribution to environmental sustainability, which positions GRBs as public goods, while private benefits have a close relationship with social and economic sustainability.

Previous studies have found that residents are prepared to pay for private benefits provided by GRBs, such as reduced utility bills. For example, Hong Kong residents are prepared to pay a premium for GRBs that reduce the cost of energy consumption by their families (Chau et al., 2010). Economic motives including a reduction in water, energy, and maintenance costs were also motivating factors for potential GRB buyers in Israel. This was also the case for residents in Sweden, where customers were willing to pay a premium for features they understood and from which they could see the potential benefits, for example, those relating to lower energy consumption by their families (Zalejska-Jonsson, 2014).

However, individual households in China obtain little benefit from reduced utility bills. The main type of GRB in China is multi-family high-rise buildings, rather than detached buildings or semi-detached buildings, as in western economies like the US. In high-rise buildings, the government and property management companies are mainly responsible for operation and maintenance (Liu et al., 2019b). Households have little control over the operation, maintenance, and retrofitting of their dwellings, and are unable to benefit from energy savings, unlike Western homeowners (Achtnicht, 2011). Even if there are energy savings in the residential estate, the beneficiaries are the property management company, instead of the developers or households. For example, energy consumption for heating in winter is one of the main 
forms of energy consumption in residential buildings, but energy savings resulting from better insulation of GRBs is not transferred to families to reduce their energy costs. Central heating is provided by municipalities in northern China, and residents are charged based on their floor area rather than on actual energy consumption. Therefore, residents are not concerned about the energy conservation performance of the building, which is one of the key benefits of GRBs in the design and operation phases. That is why most occupants are neither satisfied nor dissatisfied with energy saving-related indicators. This echoes the finding of a previous study focused on Taiwan, where approximately $37 \%$ of survey respondents were not particularly concerned about energy conservation (Liang et al., 2014). By contrast, households may be more interested in energy-saving appliances, which can reduce energy costs (Zalejska-Jonsson, 2014).

\section{Discussion and implications}

\subsection{Bridging the gap between the design and operation of GRBs}

Residential satisfaction is based on a holistic, multidimensional measurement of occupants' experiences living in GRBs. The present study identifies four dimensions of occupants' residential satisfaction with GRBs, namely, operation and maintenance, comfort and health, architectural and construction quality, and accessibility. These four dimensions are related not only to the operation phase of GRBs, but also to the planning, design, and construction phases. This reflects the fact that satisfying occupants requires whole life-cycle management and superior performance in all phases of GRBs. In addition, GRBs should meet occupants' greater social needs as well as the technical requirements of stricter building codes. 
The operation and maintenance of GRBs plays an important role in residential satisfaction, and is also a determinant of WTP for some residents. However, the results indicate that the operation and maintenance of GRBs does not satisfy residents very well. This reveals a gap between the design and operation of GRBs (Geng et al., 2018), which has partly resulted from the structure of China's GBL certification system. Under this system, there are two types of GBLs, namely, those for the design phase (GBLDs) and those for the operational phase (GBLOs) (Liu et al., 2019a). A GBLD merely provides proof of the application of sustainable strategies and practices in the planning, design, and construction phases, and provides no guarantee of the actual performance of the GRB. Evaluation of the overall performance of a green building is complex, because performance in the design phase is as important as performance in the operational phase (Asdrubali et al., 2013). A GBLO is more complicated than a GBLD, as it requires GRBs to maintain their green performance continuously over their entire life cycle. Thus, a GBLO is a more important and powerful tool in the promotion of GRBs (Li, Y. et al., 2014). However, about $95 \%$ of GBLs in Eco-city are GBLDs (Liu et al., 2019a). The classifications of GBLD and GBLO were part of a strategy to motivate stakeholders to embrace GRBs (Liu et al., 2019a). However, deficiencies in the system are emerging, and are threatening to restrict the sustainable development of GRBs in the future. Although Eco-city residents purchase and live in GRBs, they know little about the basic merits of GRBs and the limitations of the GBLD. Sales staff usually exaggerate the significance of the GBLD, and residents are typically disappointed when the building's performance does not live up to their claims. Poor operation and maintenance has resulted in the low satisfaction level of occupants. If this situation is allowed to continue, GRBs may lose 
both existing and prospective customers, and the growing number of GBLD projects will lead to an imbalance between demand and supply.

These findings serve to remind policy-makers that they need to develop a comprehensive evaluation framework for GRBs, through which stakeholders can improve overall performance rather than focusing on the maintenance of specific green technologies or facilities. A GRB is a durable good that has a long service period and involves a range of complex functions, of which environmental friendliness is only a small part. Prospective purchasers need to undertake a holistic evaluation of multiple features of GRBs in their decision-making process, and a mismatch between the performance of GRBs and the occupants' needs and expectations will lead to dissatisfaction among occupants.

Third-party institutions should be established to collect residents' feedback regarding the operation of GRBs on a regular basis and share it via the media. Since residents play an important role in monitoring the operation of GRBs, their feedback deserves more attention. Mandatory disclosure of occupancy satisfaction data would be an effective way to address the information asymmetry that exists between green design and green operations.

In addition to the above measures, governments should provide training courses and other forms of instruction to enhance stakeholders' ability to raise the standard of GRB operations. For example, technicians and other employees in property management companies should possess advanced skills enabling them to operate green facilities or smart systems embedded in GRBs. Although they are designed to be green, most of the projects with a GBLD do not achieve the desired green standard in the operational phase because of a lack of mature technologies and workers who are skilled 
and experienced in operating and maintaining those technologies. China can draw lessons from the practices of Singapore. The Building and Construction Authority of Singapore has introduced various training schemes to enhance stakeholders' competence in delivering green building projects (Liu et al., 2019a). They offer training courses and certification of specialists such as GM Facilities Managers (GMFMs) and GM Facilities Professionals (GMFPs) (Building and Construction Authority, 2009, 2015).

\subsection{Adopting a holistic view of economic, social, and environmental sustainability}

The results of our study revealed preference heterogeneity among current GRB occupants' with respect to WTP, as well as the determinants of WTP. The results showed that the mean WTP of nearly $65 \%$ of residents was $374 \mathrm{CNY} / \mathrm{m}^{2}$ (about 54 USD), which accounted for only $2.2 \%$ of housing price, far lower than the $5 \%$ reported in Sweden (Zalejska-Jonsson, 2014) and the 7-10\% found in Israel (Portnov et al., 2018).

Since the level of consumers' WTP will influence the price premium for GRBs in the housing market, developers will evaluate the necessary trade-off between their additional costs and the price premium (Liu et al., 2014). If the price premium is not sufficient to cover their additional costs, they will have no economic incentive to produce GRBs (Du et al., 2014). In this case, governments need to provide incentives that motivate them to produce GRBs, the development of which will rely on the level of the governments' financial incentives rather than on the market demand-supply mechanism, which is not a sustainable way to promote GRBs. Thus, governments should recognize the drivers of WTP and develop policies that increase residents' WTP by improving those drivers. 
Incentives are usually needed to bridge the gap between residents' WTP a price premium for GRBs and developers' additional costs. However, it has been found that offering incentives to purchase a GRB is not a good way to attract purchasers because they are more motivated by non-financial incentives (Olubunmi et al., 2016). Previous studies have found that financial incentives for GRB purchasers (such as subsidized loans) may result in a lower, rather than a higher WTP a price premium (Portnov et al., 2018). Because these types of incentives are not perceived as short-term bonds between them and the government, they prefer long-term incentives such as discounted water or electricity charges. In summary, residents' WTP cannot be sustainably motivated by limited financial incentives, but it is positively influenced by the performance of GRBs, especially by the enhanced comfort and health provided by GRBs. Therefore, government policies should focus on improving the operational performance of GRBs. Only by increasing occupants' residential satisfaction can we increase their WTP.

The relationship between residential satisfaction and WTP indicates a mutually reinforcing relationship between social sustainability and economic sustainability, which promotes environmental sustainability. This serves as a reminder to practitioners to take a holistic view when choosing sustainable ways to promote GRBs.

\section{Conclusion}

In the present study, a survey was conducted of 511 current GRB residents in Eco-city in China with the aim of determining their WTP price premium for GRBs and analyzing the impact of residential satisfaction on their WTP. Four residential satisfaction dimensions were examined, including operation and maintenance, 
comfort and health, architectural and construction quality, and accessibility of GRBs. The results showed that GRBs in Eco-city performed well in terms of providing comfort and health. However, they did not satisfy occupants very well in terms of operation and maintenance, and architectural and construction quality. All four factors were shown to be key determinants of WTP through latent class regression analysis, but their effects varied among residents, who displayed heterogeneous preferences.

Residents were divided into four segments that differed in terms of drivers and levels of WTP. The mean WTP varied significantly, ranging from $2.2 \%$ to $74.0 \%$ of the average purchase price of a GRB. Our results also showed that the aspect of comfort and health was the strongest determinant of WTP for all four types of residents, and that sociodemographic factors also affected residents' WTP, although they played different roles for different groups of residents. However, energy saving-related performance in public areas of GRBs did not play an important role in increasing residents' WTP.

The findings suggest that policy-makers need to bridge the gap between the design and operation of GRBs. In particular, the operation and maintenance of GRBs should be highlighted in addition to green design. Mandatory disclosure of occupancy satisfaction data would be an effective way to address the information asymmetry that exists between green design and green operations. Governments should also introduce training courses and other supporting forms of instruction to enhance stakeholders' ability to improve the standard of GRB operations. The assessment of WTP also suggests that incentives are needed to increase residents' WTP a premium to cover the additional costs incurred by developers of GRBs. Government subsidies to purchasers are not sustainable, and thus market-based mechanisms are preferred. Therefore, it is 
necessary to increase residents' WTP through policies targeting different groups, such as increasing the prospective benefits of GRBs in terms of comfort and health.

The present study has some limitations, which could provide directions for future research. First, although we surveyed 511 residents living in more than 30 residential estates, they were all located in Eco-city in Tianjin, and thus the representativeness of the results is limited. Second, residential experience data are derived from subjective satisfaction surveys. Although it's the frequently used method in related studies, it's subjected to other subjective influential factors that may affect the reliability of the retrieved information. We should connect their satisfaction level with actually operational performance of GRBs with discretion. Third, we did not investigate the residents' attitudes to reduced water and electricity costs, that is, the private benefits to households from energy savings. This indicator may play an important role in predicting their WTP.

\section{Acknowledgements}

This study was supported by Ministry of Education Key Research Project of Philosophy and Social Sciences (Grant Number : 15JZD025), National Natural Science Foundation of China (Grant Number: 71561137003 and 71828401), China Postdoctoral Science Foundation (Grant Number: 2019M651023), and Economic and Social Research Council, UK (Grant Number ES/N010981/1). 


\section{References}

Achtnicht, M., 2011. Do environmental benefits matter? Evidence from a choice experiment among house owners in Germany. Ecological Economics 70(11), 2191-2200.

Allen, J.G., MacNaughton, P., Laurent, J.G.C., Flanigan, S.S., Eitland, E.S., Spengler, J.D., 2015. Green buildings and health. Current Environmental Health Reports 2(3), 250-258.

Altomonte, S., Schiavon, S., 2013. Occupant satisfaction in LEED and non-LEED certified buildings. Building and Environment 68(10), 66-76.

Asdrubali, F., Buratti, C., Cotana, F., Baldinelli, G., Goretti, M., Moretti, E., Baldassarri, C., Belloni, E., Bianchi, F., Rotili, A., 2013. Evaluation of green buildings' overall performance through in situ monitoring and simulations. Energies 6(12), 6525-6547.

Baird, G., Leaman, A., Thompson, J., 2012. A comparison of the performance of sustainable buildings with conventional buildings from the point of view of the users. Architectural Science Review 55(2), 135-144.

Bonaiuto, M., Fornara, F., Ariccio, S., Cancellieri, U.G., Rahimi, L., 2015. Perceived residential environment quality indicators (PREQIs) relevance for UN-HABITAT City Prosperity Index (CPI). Habitat International 45, 53-63.

Building and Construction Authority, 2009. Second Greenbuilding Masterplan. https://www.bca.gov.sg/GreenMark/others/2nd Green_Building Masterplan.pdf, accessed Apirl 2017.

Building and Construction Authority, 2015. Third Green Building Masterplan. https://www.bca.gov.sg/GreenMark/others/3rd_Green_Building_Masterplan.pdf, accesed Apirl, 2017.

Chau, C.-K., Tse, M., Chung, K., 2010. A choice experiment to estimate the effect of green experience on preferences and willingness-to-pay for green building attributes. Building and Environment 45(11), 2553-2561.

Deng, Y., Wu, J., 2014. Economic returns to residential green building investment: The developers' perspective. Regional Science and Urban Economics 47, 35-44.

Du, P., Zheng, L.-Q., Xie, B.-C., Mahalingam, A., 2014. Barriers to the adoption of energy-saving technologies in the building sector: A survey study of Jing-jin-tang, China. Energy Policy 75, 206-216.

Geng, Y., Ji, W., Wang, Z., Lin, B., Zhu, Y., 2018. A review of operating performance in green buildings: Energy use, indoor environmental quality and occupant satisfaction. Energy and Buildings.

Hoffman, A.J., Henn, R., 2008. Overcoming the social and psychological barriers to green building. Organization and Environment 21(4), 390-419.

Hu, H., Geertman, S., Hooimeijer, P., 2014. The willingness to pay for green apartments: The case of Nanjing, China. Urban Studies 51(16), 3459-3478.

Huang, Z., Du, X., Yu, X., 2015. Home ownership and residential satisfaction: Evidence from Hangzhou, China. Habitat International 49, 74-83.

Ju, C., Ning, Y., Pan, W., 2016. A review of interdependence of sustainable building. Environmental Impact Assessment Review 56, 120-127.

Lai, J.H., 2011. Comparative evaluation of facility management services for housing estates. Habitat International 35(2), 391-397.

Li, D., Chen, H., Hui, E.C.M., Yang, H., Li, Q., 2014. A methodology for ex-post assessment of social impacts of an affordable housing project. Habitat International 43, 32-40.

Li, Q., Long, R., Chen, H., 2018. Differences and influencing factors for Chinese urban resident willingness to pay for green housings: Evidence from five first-tier cities in China. Applied Energy 229, 299-313.

Li, Y., Yang, L., He, B., Zhao, D., 2014. Green building in China: Needs great promotion. Sustainable Cities and Society 11, 1-6.

Liang, H.H., Chen, C.P., Hwang, R.L., Shih, W.M., Lo, S.C., Liao, H.Y., 2014. Satisfaction of occupants toward indoor environment quality of certified green office buildings in Taiwan. Building \& Environment 72(1), 232-242. 
Liu, Y., Guo, X., Hu, F., 2014. Cost-benefit analysis on green building energy efficiency technology application: A case in China. Energy and Buildings 82, 37-46.

Liu, Y., Hong, Z., Zhu, J., Yan, J., Qi, J., Liu, P., 2018. Promoting green residential buildings: Residents' environmental attitude, subjective knowledge, and social trust matter. Energy Policy 112, 152-161.

Liu, Y., Lu, Y., Hong, Z., Nian, V., Loi, T.S.A., 2019a. The "START" framework to evaluate national progress in green buildings and its application in cases of Singapore and China. Environmental Impact Assessment Review 75, 67-78.

Liu, Y., Shi, X., Wang, Y.P., Sun, T., 2019b. Promoting Green Residential Buildings in China: Bridging the Gap between Design and Operation to Improve Occupants' Residential Satisfaction. Sustainability 11(13), 3590.

Matisoff, D.C., Noonan, D.S., Flowers, M.E., 2016. Policy monitor-Green buildings: economics and policies. Review of Environmental Economics and Policy 10(2), 329-346.

Olubunmi, O.A., Xia, P.B., Skitmore, M., 2016. Green building incentives: A review. Renewable and Sustainable Energy Reviews 59, 1611-1621.

Portnov, B.A., Trop, T., Svechkina, A., Ofek, S., Akron, S., Ghermandi, A., 2018. Factors affecting homebuyers' willingness to pay green building price premium: Evidence from a nationwide survey in Israel. Building and Environment 137, 280-291.

Song, X., Lu, Y., Shen, L., Shi, X., 2018. Will China's building sector participate in emission trading system? Insights from modelling an owner's optimal carbon reduction strategies. Energy Policy 118, 232-244.

Vermunt, J.K., Magidson, J., 2002. Latent class cluster analysis. Applied latent class analysis 11, 89-106.

Vermunt, J.K., Magidson, J., 2005. Latent GOLD 4.0 user's guide.

Yau, Y., 2012. Willingness to pay and preferences for green housing attributes in Hong Kong. Journal of Green Building 7(2), 137-152.

Zalejska-Jonsson, A., 2014. Stated WTP and rational WTP: Willingness to pay for green apartments in Sweden. Sustainable Cities and Society 13, 46-56.

Zanuzdana, A., Khan, M., Kraemer, A., 2013. Housing satisfaction related to health and importance of services in urban slums: evidence from Dhaka, Bangladesh. Social indicators research 112(1), 163-185.

Zeng, C., Liu, S., Shukla, A., Yang, B., 2018. Identifying the occupant's satisfaction and awareness for the performance of Eco Houses in the United Kingdom. Journal of Building Engineering 18.

Zhan, D., Kwan, M.-P., Zhang, W., Fan, J., Yu, J., Dang, Y., 2018. Assessment and determinants of satisfaction with urban livability in China. Cities 79, 92-101.

Zhang, L., Sun, C., Liu, H., Zheng, S., 2016. The role of public information in increasing homebuyers' willingness-to-pay for green housing: Evidence from Beijing. Ecological Economics 129, 40-49.

Zhang, X., 2015. Green real estate development in China: State of art and prospect agenda-A review. Renewable \& Sustainable Energy Reviews 47, 1-13.

Zuo, J., Jin, X.H., Flynn, L., 2012. Social Sustainability in Construction-an Explorative Study. International Journal of Construction Management 12(2), 51-63. 


\section{Tables}

Table 1 Sample demographics

\begin{tabular}{|c|c|c|c|}
\hline Variables & Group & Frequency & Percentage \\
\hline \multirow{2}{*}{ Gender } & Male & 232 & $45.4 \%$ \\
\hline & Female & 279 & $54.6 \%$ \\
\hline \multirow{4}{*}{$\begin{array}{l}\text { Age } \\
\text { (year) }\end{array}$} & $19-30$ & 171 & $33.5 \%$ \\
\hline & $31-40$ & 278 & $54.4 \%$ \\
\hline & $41-60$ & 60 & $11.7 \%$ \\
\hline & $>60$ & 2 & $0.4 \%$ \\
\hline \multirow{5}{*}{$\begin{array}{l}\text { Income } \\
\text { (CNY) }\end{array}$} & 0 & 25 & $4.9 \%$ \\
\hline & $0-5,000$ & 184 & $36.0 \%$ \\
\hline & $5,001-10,000$ & 226 & $44.2 \%$ \\
\hline & $10,001-20,000$ & 58 & $11.4 \%$ \\
\hline & $>20,000$ & 18 & $3.5 \%$ \\
\hline \multirow{3}{*}{$\begin{array}{l}\text { Duration } \\
\text { residence } \\
\text { (year) }\end{array}$} & $1-2$ & 316 & $61.8 \%$ \\
\hline & $3-4$ & 156 & $30.5 \%$ \\
\hline & $5-6$ & 39 & $7.6 \%$ \\
\hline \multirow[t]{2}{*}{ Ownership } & Owned & 447 & $87.5 \%$ \\
\hline & Rent or others & 64 & $12.5 \%$ \\
\hline \multirow[t]{4}{*}{ Floor } & $1^{\text {st }}--3^{\text {rd }}$ & 111 & $21.7 \%$ \\
\hline & $4^{\text {th }}--6^{\text {th }}$ & 153 & $29.9 \%$ \\
\hline & $7^{\text {th-- } 9^{\text {th }}}$ & 89 & $17.4 \%$ \\
\hline & $10^{\text {th }}$ and above & 158 & $30.9 \%$ \\
\hline \multirow{5}{*}{ Number of rooms } & 1 bedroom and 1 living room & 36 & $7.0 \%$ \\
\hline & 2 bedrooms and 1 living room & 192 & $37.6 \%$ \\
\hline & 2 bedrooms and 2 living rooms & 73 & $14.3 \%$ \\
\hline & 3 bedrooms and 1 living rooms & 82 & $16.0 \%$ \\
\hline & 3 bedrooms and 2 living rooms and above & 128 & $25.0 \%$ \\
\hline Total & / & 511 & $100.0 \%$ \\
\hline
\end{tabular}


Table 2 Residential estate features of respondents' GRBs

\begin{tabular}{|c|c|c|c|c|}
\hline $\begin{array}{c}\text { Name of } \\
\text { residential estates }\end{array}$ & $\begin{array}{c}\text { No. of } \\
\text { residents } \\
\text { investigated }\end{array}$ & Plot ratio & $\begin{array}{l}\text { Ratio of } \\
\text { green space }\end{array}$ & $\begin{array}{l}\text { Management fee } \\
\text { (CNY/m²/month) }\end{array}$ \\
\hline Jiaheyuan & 62 & 1.8 & 41 & 2.98 \\
\hline Meiyunyuan & 52 & 1.4 & 42 & 3 \\
\hline Kangqiaojun & 30 & 1.1 & 40 & 3 \\
\hline Wantongxinxinyuan & 31 & 1.6 & 40 & 3 \\
\hline Hechangyuan & 28 & N/A & 40 & 1.3 \\
\hline Hongshuwanhuayuan & 27 & 2 & 35 & 2.98 \\
\hline Shimaoyingjun & 26 & 0.72 & 40 & 3 \\
\hline Baolongnanyuan & 25 & 1.5 & 40 & 2.5 \\
\hline Jinluyuan & 24 & 1.4 & 35 & $3-3.5$ \\
\hline Jingshanyuan & 21 & 1.6 & 44 & 2.68 \\
\hline Yajingyuan & 21 & 1.5 & 45 & 3 \\
\hline Jijinghuating & 18 & 1.19 & 40 & 3.4 \\
\hline Meilinyuan & 18 & 1.6 & 25 & $0.5-2.4$ \\
\hline Yihehui & 18 & 2 & 40 & 2.8 \\
\hline Shuangweiyuexinyuan & 17 & 2.49 & 40 & 3 \\
\hline Biguiyuanbinhaicheng & 15 & 1.2 & 40 & $2.5-5$ \\
\hline Kunbeiyuan & 15 & 1.4 & 40 & 2.48 \\
\hline Kunxiyuan & 14 & 1.84 & 40 & 2.48 \\
\hline Rongxinyuan & 10 & 1.6 & 40.1 & 2.96 \\
\hline Shouxiyuan & 9 & 1.3 & 38 & 3 \\
\hline Shimaojingyuan & 7 & 1.84 & 40 & 2.48 \\
\hline Yuanxionglanyuan & 7 & 1.6 & 50 & 2.8 \\
\hline Kunyuyuan & 6 & 1.4 & 40 & 2.48 \\
\hline Tianheyuan & 5 & 1.6 & 41 & 3 \\
\hline Zhongmeiqingcheng & 3 & 1.04 & 40 & 3.5 \\
\hline Shimaojiuxi & 2 & 1.4 & 40 & 3.8 \\
\hline
\end{tabular}

Data source: $\underline{w w w . k e . c o m}$, online platform of real estate agent companies. 
Table 3 Rotated component matrix

\section{Indicator}

Natural lighting

Indoor ventilation

Indoor air quality

Thermal comfort in winter

Thermal comfort in summer

Outdoor air movement

Accessibility to public transportation

Availability of shopping, catering and leisure facilities

Room soundproofing

Quality of architecture

Thermal and insulation performance of envelop

Airtightness of windows

Quality of power supply facilities

Outdoor noise

Property management

0.77

Facility Maintenance

0.76

Cleanliness

Greening

Energy saving of public areas such as corridors, staircases, etc.

Traffic layout design and management within the Eco-city

Drainage of community

\section{Component 1 Component 2 Component 3 Component 4}

0.72

0.80

0.60

0.63

0.66

0.79

Note: Factor loading less than 0.5 were not displayed. 
Table 4 Distribution of residents' WTP for price premium

\begin{tabular}{ccc}
\hline WTP/m $\left.\mathbf{m}^{2} \mathbf{C N Y}\right)$ & Percentage\% & Accumulative percentage\% \\
\hline$[1,10)$ & 19.2 & 19.2 \\
{$[10,100)$} & 4.1 & 23.3 \\
{$[100,500)$} & 15.1 & 38.4 \\
{$[500,1000)$} & 15.0 & 53.4 \\
{$[1000,2000)$} & 23.7 & 77.1 \\
{$[2000,10000)$} & 12.9 & 90 \\
$>=10000$ & 10.0 & 100.0 \\
\hline
\end{tabular}

Table 5 Model fit for different assumed models

\begin{tabular}{ccccccc}
\hline Number of class & $\mathbf{L L}$ & $\mathbf{B I C}(\mathbf{L L})$ & AIC(LL) & Npar & Class. Err. & $\mathbf{R}^{\mathbf{2}}$ \\
\hline 1-Class & -721.04 & 1479.50 & 1454.08 & 6 & 0.00 & 0.01 \\
2-Class & -62.35 & 249.42 & 164.69 & 20 & 0.02 & 0.76 \\
3-Class & -11.86 & 235.76 & 91.73 & 34 & 0.11 & 0.81 \\
4-Class & 3.02 & 293.31 & 89.96 & 48 & 0.11 & 0.85 \\
5-Class & 73.14 & 240.37 & -22.28 & 62 & 0.13 & 0.93 \\
6-Class & 70.57 & 332.82 & 10.85 & 76 & 0.13 & 0.95 \\
7-Class & 120.38 & 320.51 & -60.76 & 90 & 0.11 & 0.92 \\
8-Class & 148.64 & 351.30 & -89.28 & 104 & 0.10 & 0.90
\end{tabular}

Note: LL, Log-likelihood; BIC (LL), BIC based on log-likelihood; AIC (LL), AIC based on log-likelihood; Npar, number of parameters; Class. Err. Proportion of classification errors. 
Table 6 Estimation results of the 4-class model

\begin{tabular}{|c|c|c|c|c|c|c|c|c|c|c|}
\hline Variables & $\begin{array}{l}\boldsymbol{\beta} \\
(\mathrm{C} 1) \\
\end{array}$ & z-value & $\begin{array}{l}\beta \\
(\mathrm{C} 2) \\
\end{array}$ & z-value & $\begin{array}{l}\beta \\
(\mathrm{C} 3) \\
\end{array}$ & z-value & $\begin{array}{l}\boldsymbol{\beta} \\
(\mathrm{C} 4) \\
\end{array}$ & z-value & Wald & p-value \\
\hline \multicolumn{11}{|l|}{ Predictors } \\
\hline Zcompt1 & 0.00 & -0.54 & 0.02 & 0.76 & 0.12 & 0.81 & 0.51 & 3.49 & 13.74 & 0.01 \\
\hline Zcompt2 & 0.02 & 2.82 & 0.05 & 2.23 & 0.21 & 1.75 & -0.55 & -4.52 & 37.10 & 0.00 \\
\hline Zcompt3 & 0.01 & 1.41 & 0.06 & 2.74 & -0.12 & -0.74 & 0.15 & 1.32 & 12.09 & 0.02 \\
\hline Zcompt4 & -0.01 & -1.36 & -0.05 & -1.83 & -0.13 & -0.99 & -0.65 & -4.06 & 22.04 & 0.00 \\
\hline \multicolumn{11}{|l|}{ Covariates } \\
\hline Male & 0.23 & 0.60 & 0.61 & 1.54 & 0.51 & 1.24 & -1.36 & -1.18 & 6.56 & 0.09 \\
\hline Female & -0.23 & -0.60 & -0.61 & -1.54 & -0.51 & -1.24 & 1.36 & 1.18 & & \\
\hline $1-5,000 \mathrm{CNY}$ & 0.19 & 1.03 & -0.62 & -2.52 & -0.15 & -0.61 & 0.58 & 1.23 & 12.57 & 0.05 \\
\hline $5,001-10,000 \mathrm{CNY}$ & 0.12 & 0.68 & 0.18 & 0.78 & -0.23 & -1.06 & -0.07 & -0.15 & & \\
\hline$>10,000 \mathrm{CNY}$ & -0.32 & -1.17 & 0.44 & 1.48 & 0.38 & 1.25 & -0.51 & -0.74 & & \\
\hline $18-30$ years old & 0.15 & 0.31 & -0.22 & -0.41 & 0.29 & 0.57 & -0.22 & -0.16 & 8.05 & 0.23 \\
\hline $31-40$ years old & -0.61 & -1.61 & -0.14 & -0.32 & -0.80 & -1.95 & 1.55 & 1.38 & & \\
\hline$>40$ years old & 0.47 & 0.70 & 0.35 & 0.48 & 0.50 & 0.73 & -1.32 & -0.67 & & \\
\hline $1-2$ years living & 0.31 & 1.51 & 0.18 & 0.59 & 0.33 & 1.25 & -0.82 & -1.56 & 12.15 & 0.06 \\
\hline 3-4 years living & -0.49 & -2.51 & 0.41 & 1.45 & -0.50 & -2.02 & 0.58 & 1.40 & & \\
\hline 5-6 years living & 0.18 & 0.67 & -0.59 & -1.27 & 0.17 & 0.49 & 0.24 & 0.41 & & \\
\hline
\end{tabular}

Note: C1: Class 2; C2: Class 2; C3: Class 3; C4: Class 4; Zcompt1: Z score for component 1 Operation and maintenance; Zcompt 2: Z score for component 2 Comfort and health; Zcompt 3: Z score for component 3 Architectural and construction quality; Zcompt 4: Z score for component 4 Accessibility; 
Table 7 Profile of the 4 classes of residents

\begin{tabular}{lrlrr}
\hline Variable & $\begin{array}{l}\text { Class1: } \\
\text { Indifferent residents } \\
\text { with low WTP }\end{array}$ & $\begin{array}{l}\text { Class2: Critical } \\
\text { residents with 1000+ } \\
\text { WTP }\end{array}$ & $\begin{array}{l}\text { Class3: High WTP } \\
\text { residents driven by } \\
\text { comfort and health }\end{array}$ & $\begin{array}{l}\text { Class4: Operation } \\
\text { and maintenance } \\
\text { oriented residents } \\
\text { with 2000+ WTP }\end{array}$ \\
\hline Class Size & 0.645 & 0.189 & 0.133 & 0.033 \\
Mean of ZWTP & -0.43 & -0.24 & 2.15 & 0.80 \\
Mean of WTP & 374 & 1284 & 12575 & 2566 \\
Male & 0.40 & $\mathbf{0 . 6 2}$ & $\mathbf{0 . 5 8}$ & 0.02 \\
Female & $\mathbf{0 . 6 0}$ & 0.38 & 0.42 & $\mathbf{0 . 9 8}$ \\
1-5,000 CNY & 0.46 & 0.21 & 0.37 & 0.61 \\
5,001-10,000 CNY & 0.44 & $\mathbf{0 . 5 2}$ & 0.38 & 0.31 \\
$>$ 10,000 CNY & 0.10 & 0.27 & 0.25 & 0.08 \\
18-30 years old & 0.36 & 0.23 & 0.43 & 0.04 \\
31-40 years old & 0.51 & $\mathbf{0 . 6 5}$ & 0.44 & $\mathbf{0 . 9 5}$ \\
$>40$ years old & 0.13 & 0.12 & 0.13 & 0.00 \\
1-2 years living & $\mathbf{0 . 6 7}$ & 0.46 & $\mathbf{0 . 6 6}$ & 0.26 \\
3-4 years living & 0.24 & 0.50 & 0.25 & 0.65 \\
5-6 years living & 0.09 & 0.04 & 0.09 & 0.09 \\
\hline
\end{tabular}

Note: ZWTP for Z-score of WTP 


\section{Figures}

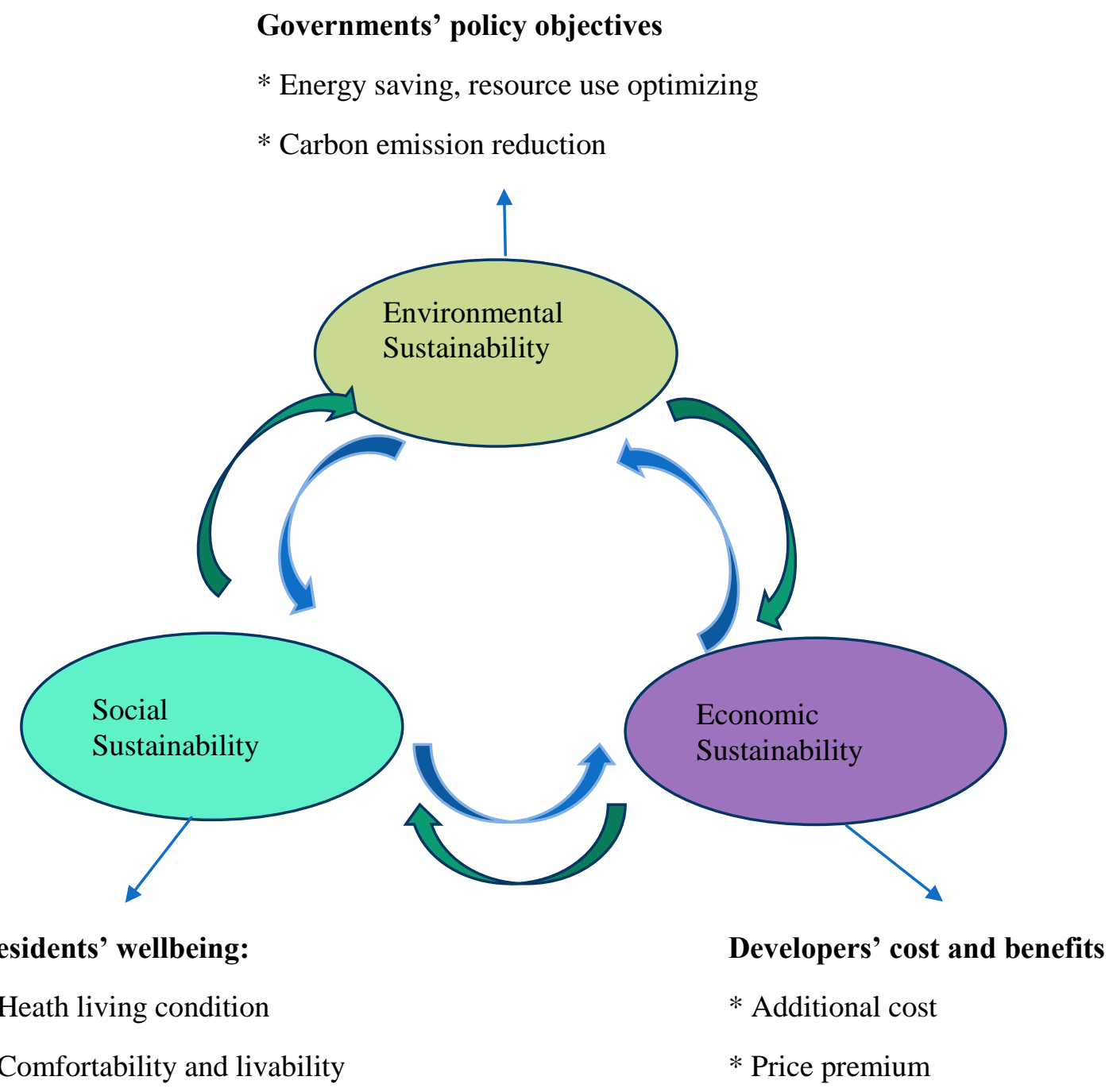

Fig. 1 Dependence of the economic, social and environmental sustainability of green housings. 


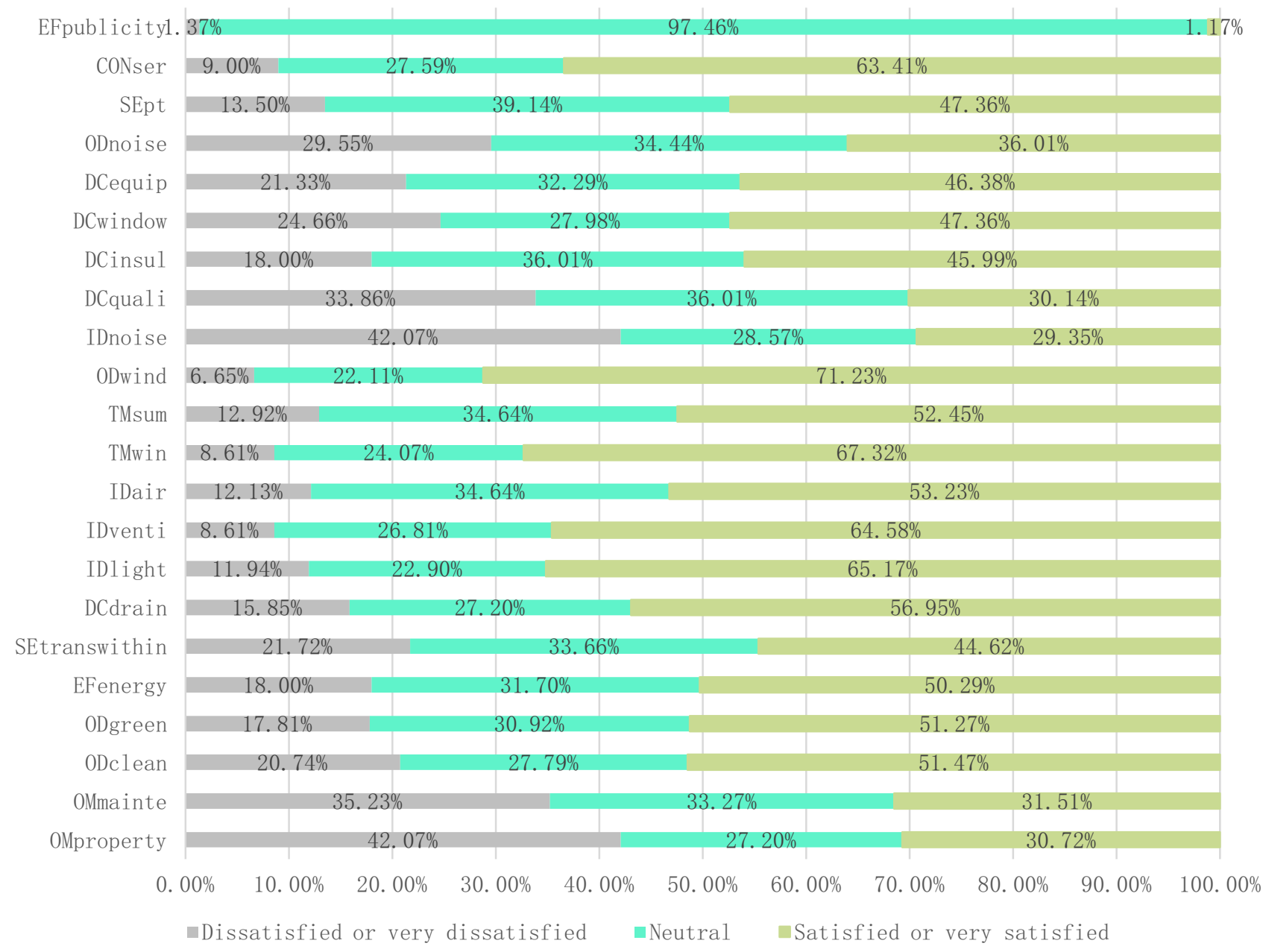

Fig.2 Residents' evaluation of their residential experiences in GRBs. Note: OMproperty for service of property management companies; OMmaite for maintenance of facilities; ODclean for cleanness of residential estates; ODgreen for the greening of residential estates; EFenergy for energy saving of public areas; SEtranswithin for internal traffic layout and management; DCdrain for drainage of residential estates; IDlight for indoor natural daylighting; INventi for indoor ventilatiom; IDair for indoor air quality; TMwin for thermal comfort in winter; TMsum for thermal comfort in summer; ODwind for outdoor air movement; IDnoise for indoor soundproofing; DCquali for construction quality; DCinsul for thermal and insulation performance of envelop; DCwindow for airtightness of windows; DCequip for quality of power supply facilities; ODnoise for noise from outdoor; SEpt for accessibility to public transport; CONser for accessibility to commercial facilities like shopping, catering and leisure, etc. EFpulicity for publicity and information campaigns about energy saving and environmental protection. 


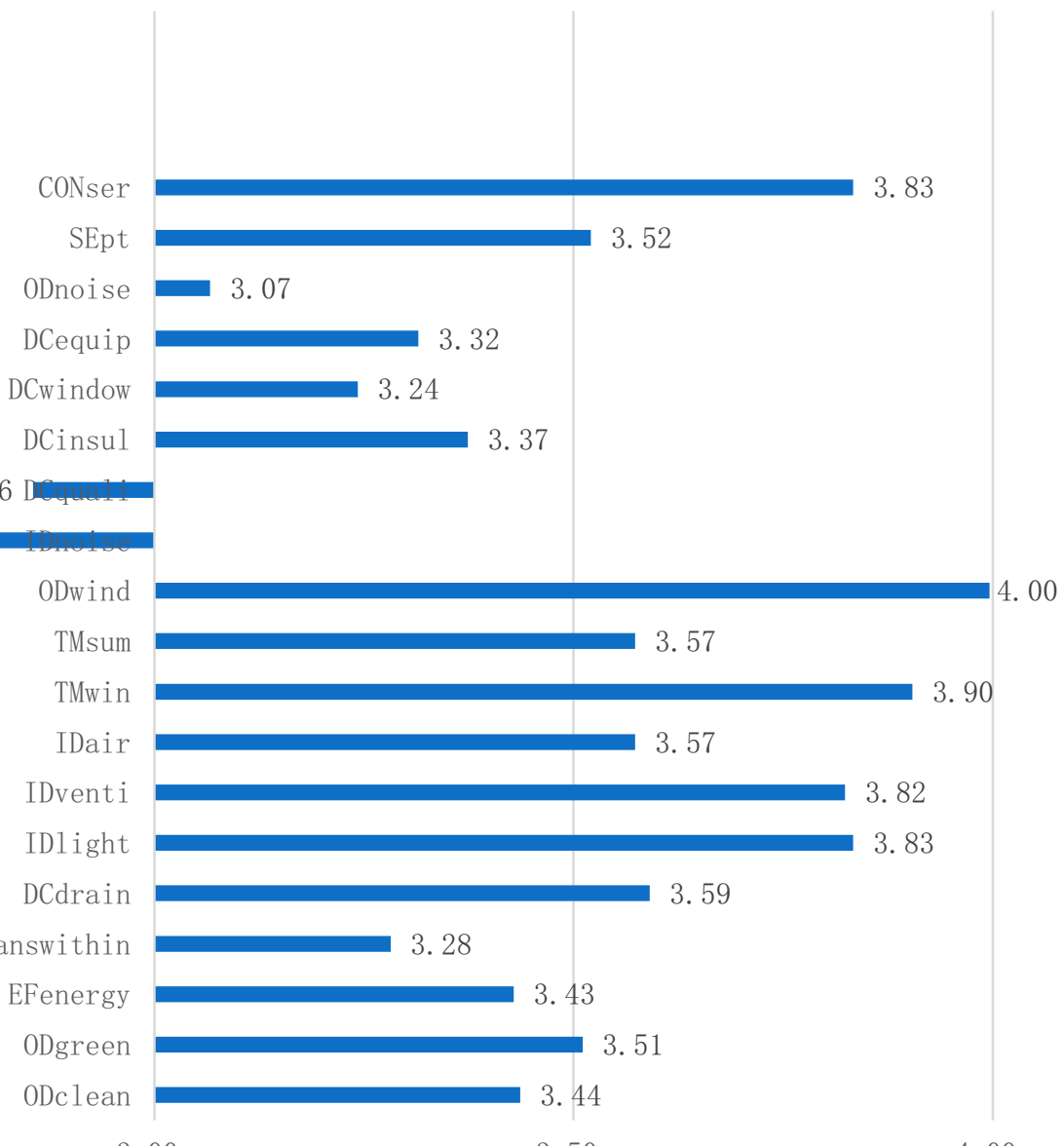

Fig. 3 Residents' overall satisfaction level on different indicators. Note: OMproperty for service of property management companies; OMmaite for maintenance of facilities; ODclean for the cleanness of residential estates; ODgreen for the greening of residential estates; EFenergy for energy saving of public areas; SEtranswithin for internal traffic layout and management; DCdrain for drainage of residential estates; IDlight for indoor natural daylighting; INventi for indoor ventilatiom; IDair for indoor air quality; TMwin for thermal comfort in winter; TMsum for thermal comfort in summer; ODwind for outdoor air movement; IDnoise for indoor soundproofing; DCquali for construction quality; DCinsul for thermal and insulation performance of envelop; DCwindow for airtightness of windows; DCequip for quality of power supply facilities; ODnoise for noise from outdoor; SEpt for accessibility to public transport; CONser for accessibility to commercial facilities like shopping, catering and leisure, etc. EFpulicity for publicity and information campaigns about energy saving and environmental protection. 


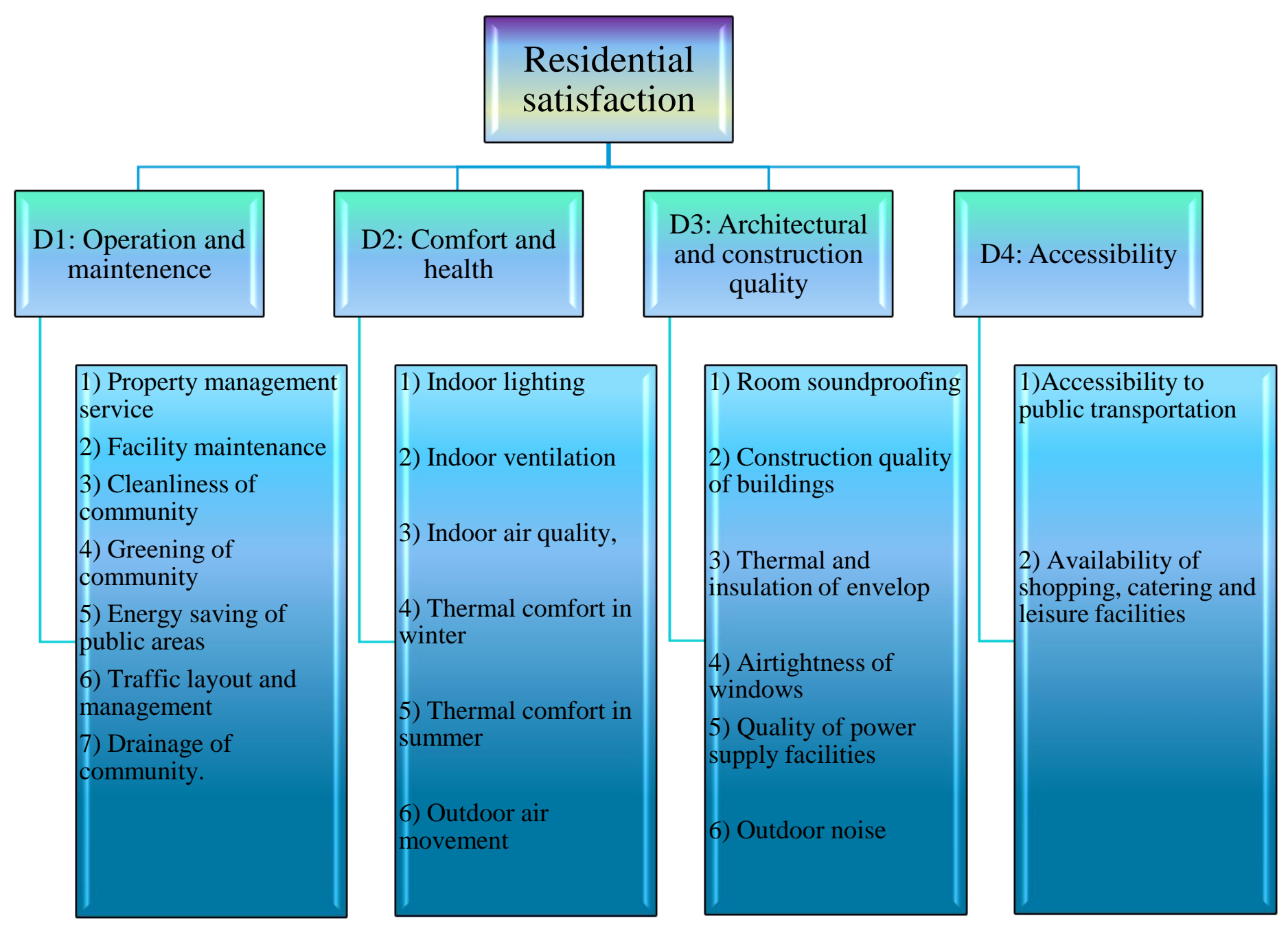

Fig. 4 Dimension of residential satisfaction 
Mean WTP: 12575

CNY(1828 USD)

Predictor : Comfort and

health,

living

age, duration of

Profile: Male (58\%), living for $1-2$ years $(66 \%)$.

Propotion: $13.3 \%$

Mean WTP: 1284 CNY(187 USD)

Predictor: Architectural and construction quality, comfort and health, accessibility, income

Profile: Male (62\%), 31-40

years old $(65 \%)$

Propotion: $18.9 \%$
Mean WTP: 2566 CNY(373

USD)

Predictor : Operation and maintenance;

Comfort and

health, accessibility

Profile: Female (98\%), 31-40 years $(95 \%)$.

Propotion: $3.3 \%$

$\square$ Class 1: Indifferent residents with low WTP

nClass 2: Critical residents with 1000+ WTP

n Class 3: High WTP residents driven by comfort and health of green housings

E Class 4: Operation and maintenance oriented residents with 2000+ WTP

Fig. 5 Heterogeneity of residents' WTP 